\title{
Las contradictorias exigencias a la Educación Superior en Chile
}

\author{
Colomba Norero V. \\ The contradictory requirements \\ of university teaching in Chile
}

\begin{abstract}
Chile should become a member of the "society of knowledge". Therefore, undergraduate curricula of university careers should be revised, to offer shorter programs that prepare for a permanent training during the whole professional life. This proposal requires an agile academic team, endowed with the adequate methodological tools, but also a contingent of interested and motivated students with comprehension and expression skills and a study discipline. This article comments on the training deficiences of students that are admitted to Chilean universities and the difficulties of university teachers to compensate this training deficiencies in order to teach their subjects in shorter lapses (Rev Méd Chile 2007; 135: 1343-5).
\end{abstract}

(Key words: Curriculum; Education, premedical; Students)

Recibido el 2 de junio, 2007. Aceptado el 3 de julio, 2007.

Vicedecana de la Facultad de Ciencias de la Salud, Universidad Andrés Bello. Miembro de Número, Academia Chilena de Medicina. Santiago de Chile

L os desafíos que se presentan a la Educación Superior en Chile son de gran envergadura y se relacionan con aspectos de institucionalidad, gestión y financiamiento del sistema que han sido muy debatidos desde hace largo tiempo ${ }^{1-5}$. En esta ocasión me quiero referir sólo a dos puntos que son muy contradictorios entre sí: uno es la necesidad del país en ingresar a la llamada «sociedad del conocimiento»y y el otro son las deficiencias evidentes y cada vez más marcadas de la educación preuniversitaria en Chile $^{6-8}$.

En relación a la situación educacional basal, si bien debe destacarse los esfuerzos realizados para incorporar un número mayor de jóvenes a la educación supenior y se exhibe como logro que 38\% de aquellos en edad de cursar estudios supeniores pueda llegar a la universidad $\mathrm{y}$, especialmente, que una

Correspondencia a: Dra. Colomba Norero. Sazié 2212. Santiago, Chile. E mail: cnorero@gmail.com proporción creciente de ellos son la primera generación de su familia que logra ese acceso -todos elementos que apuntan a la equidad ${ }^{9}$ - también debe señalarse la creciente insatisfacción de los docentes universitarios sobre la calidad de los alumnos que acceden a las aulas universitarias chilenas.

Ya no sólo se trata de lo que no saben (eso se puede remediar), sino de su actitud ante el aprendizaje derivada de la limitada formación de su capacidad de entender y expresarse, como elementos básicos para la adquisición del conocimiento. Quizás, lo peor, es su falta de motivación, aunque para ser justos ello no debe generalizarse.

\section{EXPLICACIONES PARA ESTA SITUACIÓN}

El ambiente intelectual del país no contribuye adecuadamente a despertar inquietudes, asombro o interés: no se ha logrado desarrollar un hábito de lectura, es penosa la falta de concurrencia de 
gente joven a los museos y conferencias de alto nivel, incluso gratuitas, y la televisión es más bien aplanadora de intelectos.

En los adolescentes se aprecia una evidente satisfacción en aturdirse con los videojuegos 0 con estimulantes artificiales, con una irresponsabilidad abismal si se piensa en las temibles consecuencias de estas conductas.

Las universidades chilenas han sido uno de los grandes culpables, al abandonar la formación de los profesores de enseñanza media, hace décadas, $\mathrm{y}$ eso se ha hecho notar con crudeza en los recientes resultados de los exámenes nacionales para ingreso a las universidades.

Esta situación es culpa de todos pero, fundamentalmente, de las generaciones que dejamos que las cosas tomaran el rumbo actual, por nuestra indiferencia, indolencia, crítica fácil y no constructiva. Pueden darse explicaciones de orden sociológico como el cansancio o la desilusión, pero el hecho está ahí: tenemos una tremenda deuda con nuestra juventud que no se paga con conceptos teóricos de mayor equidad y calidad, sino con la elaboración de planes ajustados a nuestra realidad, sintonizados (palabra de moda) con nuestras deficiencias, apegados a solucionar nuestras falencias básicas.

Ello se refuerza al constatar que, en el mismo tiempo, muchos países fueron capaces de entender que el mayor esfuerzo de sus gobiemos debía ir dirigido a la educación. Notables ejemplos, especialmente por su favorable cambio en períodos cortos de tiempo han sido Irlanda y Finlandia. Sin conocer el detalle de cómo lo lograron, creo que el tema de obediencia a normativas bien concebidas debe haber jugado un papel muy importante.

Creo que nadie puede discutir la fundamental importancia de los educadores de enseñanza media en este proceso. Tampoco que como docentes deben actualizar sus conocimientos y ser evaluados periódicamente, recibiendo sueldos adecuados y reconocimiento social, este último ganado por el respeto de la población a la labor efectuada por ellos.

Así, la necesaria y urgente mejonía de la educación a todo nivel debe realizarse con una estrategia que apunte a obtener logros en la actitud en docentes y alumnos que permitan el posterior desamollo de recursos humanos calificados y la inserción del país en una indispensable internacionalización.
EN RELACIÓN A LA GLOBALIZACIÓN Y LA EMERGENCIA DEL CONCEPTO DE LA SOCIEDAD DEL CONOCIMIENTO

La globalización es una consecuencia inevitable de la rapidez de las comunicaciones y trae implícito consigo un fuerte componente tecnológico ${ }^{10}$.

En Chile, los aspectos económicos se han logrado desarrollar con bastante facilidad en esta especie de acuerdo mundial respecto a reglas del juego, porque ya existía un ambiente favorable de larga data.

En lo que se refiere a ciencias, la comunidad científica mundial nunca ha tenido reales fronteras. Las líneas de pensamiento se han desarrollado en forma sincrónica - de allí que no debe extrañar la simultaneidad de los hallazgos científicos- y se comparte (y se compite) por la adquisición de nuevos conocimientos. Estos se publican, difunden con extraordinaria rapidez y se ponen en práctica en forma inmediata: hay aquí una real globalización con evidentes implicancias económicas del poder que este conocimiento significa. De allí la emergencia de la ssociedad del conocimiento»en que los que crean el conocimiento son piezas claves pero en ningún caso definitorias ante el entramado económico que hay detrás. Por ello existe una necesidad evidente de formación de personal calificado para manejar y crear nuevo conocimiento, en esta maquinaria de intensos ribetes tecnológicos.

Como respuesta a estas necesidades vino la revisión de los curricula de las carreras profesionales, especialmente en Europa, donde el establecimiento de la Unión Europea -con toda la amplitud económica, cultural y geográfica que ello significa- obligaba a dar oportunidades a las personas ante esta globalización conceptual y teritorial. De allí surgió la idea de la «educación permanente», en que se acorta la duración del pregrado y se ofrecen magísteres de carácter profesional que mantengan al día a los profesionales de cualquier país de la comunidad porque se asegura un sistema de crédito transferible entre las universidades, lo que favorece la movilidad ${ }^{11}$. Esto significa que hay una equivalencia de calidad entre los contenidos entregados en los distintos campus universitarios e implica también un contingente de personas que ingresan a la educación superior con una base intelectual firme y un decidido propósito de mantener una actitud formativa de por vida. 
Indudable que esto es de una concepción teórica impecable. Sin embargo uno se preocupa del énfasis en lo tecnológico, en la formación dirigida a las competencias específicas de cada carrera profesional, como meta primordial. Obvio que esto parece no criticable. Sin embargo, si bien los profesionales deben estar formados para el servicio de la gente, para solucionarles sus problemas e inquietudes, también deben ser formados como agentes de incremento intelectual, como líderes de opinión y no como meros actores de soluciones técnicas. La tendencia a dejar de lado los aspectos humanísticos en las profesiones técnicas ha despertado felizmente una respuesta de resurgimiento de dicha enseñanza en la totalidad de la formación universitaria.

\section{¿Cuál es la paradoja en Chile EN CUANTO A EDUCACIÓN SUPERIOR?}

Por un lado, debemos asimilarnos a los conceptos de educación profesional de pregrado acortada para dar posibilidades de diversificación posterior, con una permanente actualización y movilidad,

\section{REFERENCIAS}

1. Informe de la Comisión Nacional de Modernización. Presidencia de la República, agosto 1994.

2. UnESCO: Directrices en materia de calidad de la educación superior a través de las fronteras. París. Ed Unesco, 2006.

3. BeLEI C. ¿Ha tenido impacto la reforma educativa chilena? En: Políticas educacionales en el cambio de siglo. Ed Cristián Cox. Editorial Universitaria 2003. Capítulo 3, págs 125-206.

4. Proyecto de ley que establece la Ley General de Educación. Mensaje 55-355 de Presidencia de la República a Cámara de Diputados 9 de abril de 2007.

5. Consejo Asesor Presidencial para la Calidad de la Educación. Informe final. 11 de noviembre de 2006.

6. Ministerio de Educación. Simce. Principales resultados nacionales www.simce.cl (Consultado mayo 2007). pero debemos trabajar con un contingente de alumnos egresados de la enseñanza media que no están preparados para cumplir esa tarea, porque necesitan un tiempo relativamente largo para adquirir una actitud de aprendizaje que no traen desde sus colegios. Tampoco los docentes universitarios estamos preparados para cumplir ambos cometidos, que requieren de una flexibilidad y un grado de adaptación extraordinario.

Pareciera así que toda mejońa de la educación debe partir por la capacitación docente en todos los niveles educativos, como un paso imprescindible.

Desgraciadamente, los cambios educativos tienen una latencia importante en concretarse y hemos perdido tiempo valioso. Ojalá las decisiones que se tomen en la actuales Comisiones de Estudio ${ }^{4,12}$ lleven a una estrategia que no sólo se refiera a los aspectos principalmente cautelados hasta ahora, como son los temas económicos y la supervisión de actividades, sino a elaborar planes formativos que abarquen una visión global del problema educativo como un imperativo ético nacional. Dichos planes deben recibir un respaldo generoso, más allá de los intereses locales, probablemente bien intencionados pero que tienen visiones sesgadas y de corto plazo.

7. Ministerio de Educación Simce 2006. Niveles de logros. Lectura y Matemáticas www.mineduc.cl (Consultado mayo 2007).

8. TIMSS. Chile y el aprendizaje de matemáticas y ciencias. Niveles de logro www.sector matemáticas.cl/timss (Consultado mayo 2007).

9. LeIVA A. Ejes para la elaboración de una política para la educación superior. En: Políticas públicas para la educación superior. CSE 2005; 37-52.

10. SalazAR JM. La globalización y sus efectos en la educación superior. ¿Hacia dónde vamos? En: La Educación Superior en Chile. Estudios II. Anales del Instituto de Chile 2005-2006: vol XXV; 57-73.

11. PEY R. Una reflexión sobre la internacionalización de la Educación Superior y los desafíos para las universidades chilenas. En: La Educación Superior en Chile. Estudios II. Anales del Instituto de Chile 2005-2006; 75-87

12. Comisión Asesora Presidencial de Educación Superior. Constitución el 5 de abril de 2007. 